Disclosure of Interests: None declared

DOI: 10.1136/annrheumdis-2019-eular.5251

\section{AB1265 EVALUATION OF ADHERENCE TO TREATMENT IN PATIENTS OF RHEUMATIC DISEASES}

Svetlana Yakupova ${ }^{1}$, Elza Fatykhova ${ }^{2}$, Venera Mukhamadieva ${ }^{3}$, Igor Serdyuk ${ }^{4}$, Rifkat Abdrakipov ${ }^{5}{ }^{1}$ KSMU, Department of Hospital therapy, Kazan, Russian Federation; ${ }^{2}$ KSMU, Hospital therapy, Kazan, Russian Federation; ${ }^{3}$ KSMU, Kazan, Russian Federation; ${ }^{4}$ Republican Clinical Hospital, Center of rheumatology, Kazan, Russian Federation; ${ }^{5}$ Republican Clinical Hospital, Rheumatology, Kazan, Russian Federation

Background: Patient adherence to treatment is one of the most important factors influencing the effectiveness of therapy, the course of the disease and the prognosis of the patient's life. In addition to understanding the degree of adherence, it is important to study the factors that reduce patient adherence. In 2008, the Russian questionnaire for evaluation of adherence to treatment was developed, assessing adherence to drug therapy, to medical care, to lifestyle modification and general adherence to treatment. The questionnaire showed good sensitivity (93\%) and specificity $(78 \%)$.

Objectives: Using the questionnaire, assess the level of adherence to treatment, to drug therapy, medical care and to to lifestyle modification of patients with rheumatic diseases.

Methods: The study included 130 patients (30 men and 100 women) with rheumatic diseases observed in the hospital (63.1\%) or outpatien $(36.9 \%)$. The average age of patients was $53.1 \pm 11.72$ years (from 27 to 81$) .69$ patients $(53 \%)$ suffered with rheumatoid arthritis, with ankylosing spondylarthritis $21(16.2 \%)$, with osteoarthritis $13(10 \%)$, with psoriatic arthritis and systemic vasculitis in 7 patients $(5.4 \%)$, the remaining $10 \%$ were other rheumatic diseases. The average disease duration is 12.3 years. Patients received NSAIDs $(83.8 \%)$, glucocorticoids $(62.3 \%)$, methotrexate $(39.2 \%)$, immunosuppressive specialty drugs $(23 \%)$, cyclophosphamide $(3.8 \%)$, hydroxychloroquine $(3 \%)$, sulfasalazine $(2,3 \%)$, leflunomide $(1.5 \%)$, azathioprine $(0.8 \%)$. Based on the data obtained in points and comparing them with theoretically possible, the level of adherence was assessed as high (76\% or more), medium $(51-75 \%)$ and low $(50 \%$ or less).

Results: The high level of adherence was observed only in 12 people $(9.2 \%)$, in 66 patients $(50.8 \%)$ - medium and in 52 people $(40 \%)$ - low Men had a higher level of adherence (57.6\%) than women (55.4\%). Among those using non-traditional methods of treatment $(33.1 \%)$, adherence to treatment was $54.5 \%$, for non-applicants $(66.9 \%)$ the level of adherence was higher - $56 \%$.

The average level of adherence to drug therapy was $61 \%$, to medical care - $65 \%$, to lifestyle modification - only $48.8 \%$. The degree of adherence to lifestyle changes was slightly higher among women - $48.3 \%$ than among men $-47.6 \%$. Patients suffering from rheumatic diseases from 5 to 10 years $-53.4 \%$ had a higher level of adherence to lifestyle changes than patients suffering from less than 5 years $(48.2 \%)$ and more than 10 years $(45.2 \%)$. Patients with osteoarthritis have a higher level of adherence to treatment (58\%) than patients with rheumatoid arthritis $(55.8 \%)$ ankylosing spondyloarthritis (56\%), and psoriatic arthritis (56.1\%).

Conclusion: In patients with rheumatic diseases, $40 \%$ showed a low level of adherence to treatment, $50.8 \%$ - an average level, which indicates a lack of adherence. The lowest level of adherence is noted for modifying the lifestyle - $48.8 \%$, which depended on the sex and duration of the disease.

\section{REFERENCES}

All these factors must be considered when discussing the strategy and tactics of treatment with each patient in real clinical practice.

Disclosure of Interests: None declared

DOI: 10.1136/annrheumdis-2019-eular.6537

\section{AB1266 THE CORRELATION BETWEEN SMOKING AND DISEASE ACTIVITY AND MRI INFLAMMATION IN EARLY AXIAL SPONDYLOARTHRITIS IN AN EGYPTIAN COHORT}

fatma fayed, Abeer Abdelati. Alexandria, rheumatology and immunology unit, Alexandria, Egypt

Background: literature suggests that smoking is one of the crucial triggering factors of rheumatological diseases. (1) In axial Spondyloarthritis (axSpA), classified into radiographic SpA (AS) and non-radiographic SpA
(nrSpA), smoking associated with disease activity and extra-articular manifestation. (2) The relationship between smoking and HLAB-27 as well as $\mathrm{MRI}$ inflammation in axSpA patients and the difference between nrSpA and AS regarding smoking have not been studied to date in details.

Objectives: to investigate the influence of smoking on disease activity and MRI inflammation in axSpA patients (AS and $\mathrm{nrSpA}$ ).

Methods: sixty Egyptian patients (42 males and 18 females) with the mean age (31.33 \pm 7.02 ), with early active axial spondyloarthritis (49 AS and 11 non-radiographic $\mathrm{SpA}$ ) within two years disease duration, diagnosed based on ASAS classification criteria. All clinical indices (BASDI BASFI, BASMI, ASDAS-CRP) were applied to all patients. HLA-B27 and the inflammatory markers (ESR, CRP) was done. MRI of sacroiliac joints was performed in a standard protocol using short tau inversion recovery and $\mathrm{T} 1$ sequences (slice thickness $3-4 \mathrm{~mm}$, both semi-coronal and semiaxial orientations), and scored by the Berlin method. Smoking use assessed by smoking pack-year index.

Results: of all 60 patients, 38 smokers and 22 non-smokers. No significant difference regarding smoking packs index between $\mathrm{nrSpA}$ and $\mathrm{AS}$ $(p=0.822)$ There was a robust correlation between smoking packing index and the Berlin score of $\mathrm{MRI}$ in all axSpA patients $\left(r_{\mathrm{s}=} 0.631\right)$ $(p=<0.001)$. Moreover, there was a significant correlation between smok ing and C-reactive protein $\left(r_{s=} 0.952\right)$ as well as HLA-B27. $\quad\left(r_{s=} 0.340\right)$ $(p<0.001)$ Furthermore, a significant relationship between smoking and activity indices (BASDI $\left(r_{\mathrm{s}=}\right.$ 0.961) and ASDAS-CRP $\left(r_{\mathrm{s}=0.938)}\right)$. Other wise, no significant correlation among smoking, BASMI, and BASFI as well as ESR.

Table (1): Correlation between smoking pack index and different parameters

\begin{tabular}{llcccccc}
\hline Disease activity & \multicolumn{5}{c}{ Smoking pack index } \\
\cline { 2 - 7 } & $\begin{array}{l}\text { Non radiographic SpA } \\
(\mathbf{n}=11)\end{array}$ & $\begin{array}{c}\text { Radiographic SpA } \\
(\mathbf{n}=49)\end{array}$ & $\begin{array}{c}\text { Total } \\
(\mathbf{n}=60)\end{array}$ \\
\cline { 2 - 7 } & $\mathbf{r}_{\mathbf{s}}$ & $\mathbf{p}$ & $\mathbf{r}_{\mathbf{s}}$ & $\mathbf{p}$ & $\mathbf{r}_{\mathbf{s}}$ & $\mathbf{p}$ \\
\hline BASDI & $0.986^{*}$ & $<0.001^{*}$ & 0.224 & $<0.001^{*}$ & 0.204 & $<0.001^{*}$ \\
ASDAS-CRP & $0.981^{*}$ & $<0.001^{*}$ & $0.969^{*}$ & $<0.001^{*}$ & $0.938^{*}$ & $<0.001^{*}$ \\
\hline
\end{tabular}

$r_{s}$ : Spearman coefficient*: Statistically significant at $p \leq 0.05$

Table (2): Correlation between smoking pack index and HLAB27, inflammatory marker (CRP) and Berlin score of MRI

\begin{tabular}{lccccccc}
\hline & \multicolumn{5}{c}{ Smoking pack index } \\
\cline { 2 - 7 } & $\begin{array}{l}\text { Non radiographic SPA } \\
(\mathbf{n}=\mathbf{1 1})\end{array}$ & \multicolumn{2}{c}{$\begin{array}{c}\text { Radiographic SPA } \\
(\mathbf{n}=\mathbf{4 9})\end{array}$} & $\begin{array}{c}\text { Total } \\
(\mathbf{n}=60)\end{array}$ \\
\cline { 2 - 7 } & $\mathbf{r}_{\mathbf{s}}$ & $\mathbf{P}$ & $\mathbf{r}_{\mathbf{s}}$ & $\mathbf{p}$ & $\mathbf{r}_{\mathbf{s}}$ & $\mathbf{p}$ \\
\hline HLAB27 & $0.602^{*}$ & $0.049^{*}$ & $0.293^{*}$ & $0.041^{*}$ & $0.340^{*}$ & $0.008^{*}$ \\
Berlin score of MRI & $0.687^{*}$ & $0.020^{*}$ & $0.742^{*}$ & $<0.001^{*}$ & $0.631^{*}$ & $<0.001^{*}$ \\
CRP & $0.991^{*}$ & $<0.001^{*}$ & $0.970^{*}$ & $<0.001^{*}$ & $0.952^{*}$ & $<0.001^{*}$ \\
\hline
\end{tabular}

$r_{\mathrm{s}}$ : Spearman coefficient

*: Statistically significant at $p \leq 0.05$

Conclusion: Smoking has no significant difference between AS and nrSpA. Smoking has a significant association with HLA-B27, the inflam matory lesions of $\mathrm{MRI}$, and clinical indices (BASDI, ASDAS-CRP) as well as $C$ reactive protein in $A S$ and non-radiographic $S p A$ patients while it has no association with the other clinical indices in term of BASMI and BASFI as well as the Erythrocyte sedimentation rate (ESR).

\section{REFERENCES}

[1] Belbasis L, Dosis V, Evangelou E. elucidating the environmental risk factors for rheumatic diseases: An umbrella review of meta analyses. International journal of rheumatic diseases. 2018;21(8):1514-24

[2] Zhao S, Jones GT, Macfarlane GJ, et al. Associations between smoking and extra-axial manifestations and disease severity in axial spondyloarthritis: results from the BSR Biologics Register for Ankylosing Spondylitis (BSRBR-AS). Rheumatology2018.

Disclosure of Interests: None declared

DOI: 10.1136/annrheumdis-2019-eular.7771 